\title{
Developing New Marine Antifouling Surfaces: Learning from Single-Strain Laboratory Tests
}

\author{
Sara I. Faria ${ }^{1,+}$, Luciana C. Gomes ${ }^{1,+} \mathbb{D}$, Rita Teixeira-Santos ${ }^{1}$, João Morais ${ }^{2} \mathbb{D}$, Vítor Vasconcelos ${ }^{2,3} \mathbb{D}$ \\ and Filipe J. M. Mergulhão ${ }^{1, *(D)}$
}

1 LEPABE-Laboratory for Process Engineering, Environment, Biotechnology and Energy, Faculty of Engineering, University of Porto, Rua Dr. Roberto Frias, 4200-465 Porto, Portugal; sisf@fe.up.pt (S.I.F.); luciana.gomes@fe.up.pt (L.C.G.); ritadtsantos@fe.up.pt (R.T.-S.)

2 CIIMAR-Interdisciplinary Centre of Marine and Environmental Research, University of Porto, Terminal de Cruzeiros do Porto de Leixões, Avenida General Norton de Matos, S/N, 4450-208 Matosinhos, Portugal; jmorais@ciimar.up.pt (J.M.); vmvascon@fc.up.pt (V.V.)

3 FCUP_Faculty of Sciences, University of Porto, Rua do Campo Alegre, 4069-007 Porto, Portugal

* Correspondence: filipem@fe.up.pt; Tel.: +351-225081668

+ These authors contributed equally to this work.

Citation: Faria, S.I.; Gomes, L.C.;

Teixeira-Santos, R.; Morais, J.

Vasconcelos, V.; Mergulhão, F.J.M.

Developing New Marine Antifouling Surfaces: Learning from Single-Strain Laboratory Tests. Coatings 2021, 11,

90. https://doi.org/10.3390/ coatings11010090

Received: 17 December 2020 Accepted: 11 January 2021

Published: 15 January 2021

Publisher's Note: MDPI stays neutral with regard to jurisdictional clai$\mathrm{ms}$ in published maps and institutional affiliations.

Copyright: $(\odot 2021$ by the authors. Licensee MDPI, Basel, Switzerland. This article is an open access article distributed under the terms and conditions of the Creative Commons Attribution (CC BY) license (https:// creativecommons.org/licenses/by/ $4.0 /)$.

\begin{abstract}
The development of antifouling (AF) technology for marine environments is an area of intense research given the severe economic and ecological effects of marine biofouling. Preliminary data from in vitro assays is frequently used to screen the performance of AF coatings. It is intuitive that microbial composition plays a major role in surface colonization. The rationale behind this study is to investigate whether using a mixed population for the in vitro tests yields substantially different results than using single strains during initial screening. A polymeric coating was tested against single- and dual-species cultures of two common microfouler organisms for 49 days. A bacterium (Pseudoaltermonas tunicata) and a cyanobacterium (Cyanobium sp. LEGE 10375) were used in this study. Linear regression analysis revealed that Cyanobium sp. biofilms were significantly associated with a higher number of cells, wet weight, thickness, and biovolume compared to dual-species biofilms. P. tunicata alone had a biofilm growth kinetics similar to dual-species biofilms, although the P. tunicata-Cyanobium sp. mixture developed less dense and thinner biofilms compared to both single-species biofilms. Cyanobium sp. LEGE 10375 biofilms provided the worst-case scenario, i.e., the conditions that caused higher biofilm amounts on the surface material under test. Therefore, it is likely that assessing the AF performance of new coatings using the most stringent conditions may yield more robust results than using a mixed population, as competition between microfouler organisms may reduce the biofilm formation capacity of the consortium.
\end{abstract}

Keywords: marine biofouling; single-species biofilm; multispecies biofilm; antifouling coating

\section{Introduction}

Marine biofouling is a colonization process that starts when a surface material is immersed in seawater and leads to the development of complex biological communities called biofilms [1]. This undesirable attachment of molecules and fouling organisms to submerged surfaces causes economic losses to human activities in the sea, including maritime transport, water desalination, aquaculture, and oil and gas industries [2]. Indeed, the main problems of biofouling on marine vessels are related to the corrosion and increased frictional effects created by the presence of organisms on the vessel surface [3]. This can reduce the maneuverability of ships due to their increased weight and reduced speed, resulting in increased fuel consumption [3,4]. High levels of biofouling activity can also lead to the increased frequency of dry-docking operations and an overall reduction of the integrity of the ship hulls, factors that have significant financial impacts on the vessel owners [4]. Additionally, biofouling communities have the potential to transport invasive 
non-native species across geographical niches, which can have disastrous effects on native populations and communities [5]. Therefore, the need to protect submerged surfaces from biofouling organisms is of economic and environmental importance.

The scientific community has been focusing its efforts on overcoming these problems by developing antifouling (AF) coatings [6]. The most well-consolidated and commercially established AF coatings are biocide-containing paints [7], typically employing copper or zinc as the active ingredient $[6,8]$. However, alternative protective AF coatings are being developed, taking into account new rigid international regulations and environmental concerns. At present, there are two major environmentally-friendly antifouling strategies, which are foul release coatings [7,9] and bioinspired coatings that prevent the settlement of organisms through their surface properties (e.g., micro- or nano-structured "self-cleaning" surfaces) $[10,11]$.

For testing the performance of novel antifouling coatings, these should be first screened under laboratory conditions that mimic the marine environment since the direct evaluation of coatings in the ocean would be very expensive due to the large quantities of test products and prolonged immersion times that are required. Additionally, field tests have their own drawbacks, like the ecotoxicity of some biocide-release coatings [12].

Several factors may influence the efficacy of an AF coating, including the water temperature and salinity, available nutrients, hydrodynamics, and organisms that can vary significantly depending on the sea site $[1,13]$. It is described that marine biofilms are mainly composed of different species of bacteria and diatoms [2]. The most studied biofilm communities are those established in the euphotic zones of aquatic habitats, comprising photoautotrophic microorganisms, such as diatoms, green algae, and cyanobacteria, which produce the organic carbon that fuels the life of heterotrophic microorganisms, such as bacteria [14]. Although diatom-bacteria co-cultures under photoautotrophic conditions would be more realistic than single monocultures, there are only a few test systems at a laboratory scale using such mixed cultures $[12,14]$. The study of multispecies biofilms may be limited by the complexity of each community and the lack of knowledge regarding the identity and abundance of each biofilm resident, which makes it difficult to select the organisms for the in vitro assays, as well as by some technical limitations associated with different biofilm setups [15]. Furthermore, although it is described that the physiology and function of these complex communities differ from those of the individual species when examined as monocultures [16,17], it has recently been proven that increasing culture diversity beyond a threshold has little effect on interspecies interactions and biomass production $[18,19]$. The rationale behind the present work is whether there are benefits in varying the degree of complexity of marine cultures when the goal is to get the first indications about the AF materials' performance. A polymeric coating commonly used to coat the hulls of small recreational vessels and with known antibiofilm activity [20] was tested against mono-species (Pseudoalteromonas tunicata or Cyanobium sp. LEGE 10375) and dual-species cultures (P. tunicata-Cyanobium sp. LEGE 10375) in order to identify which culture conditions generate the worst-case scenario, and thus the most appropriate in vitro experiments for the initial screening of the performance of novel AF marine surfaces.

\section{Materials and Methods}

\subsection{Surface Preparation}

A glass surface coated with a polymer epoxy resin was tested for single- and dualspecies biofilm formation. Epoxy resins are typically used to coat the hulls of small recreation vessels (e.g., powerboats, yachts, sailing boats) $[21,22]$ since they contribute to the production of stiffer, stronger, lighter hulls with improved structural stability and hydrodynamic performance [23]. Furthermore, they can have antifouling activity [20]. Glass coupons $\left(1 \times 1 \mathrm{~cm}^{2}\right.$; Vidraria Lousada, Lda, Lousada, Portugal) were firstly washed and sterilized as fully described in Faria et al. [20], and then coated with $70 \mu \mathrm{L}$ of a polymer epoxy resin (HB Química, Matosinhos, Portugal) by spin coating (Spin150 Polos ${ }^{\mathrm{TM}}$, Paralab, Porto, Portugal) at $6000 \mathrm{rpm}$ for $40 \mathrm{~s}$, with increments of $1000 \mathrm{rpm}$. Coated surfaces were dried in 
two different steps (12 h at room temperature and $3 \mathrm{~h}$ at $60^{\circ} \mathrm{C}$ ) as previously described [20]. Surfaces were sterilized by immersion in $70 \%(v / v)$ ethanol (VWR International S.A.A., Fontenay-sous-Bois, France) for $20 \mathrm{~min}$ and air-dried inside a flow chamber to maintain sterility. The initial weight of each coupon was determined before experiments.

\subsection{Marine Organisms and Culture Conditions}

One marine bacterium-Pseudoalteromonas tunicata DSM 14096-and one cyanobacterium -Cyanobium sp. LEGE 10375-were the microorganisms chosen for this study since they are recognized as early colonizers in the fouling process [2]. Additionally, they are typically present in the euphotic zone of a marine ecosystem, where the best characterized multispecies biofilms are developed [14].

P. tunicata (DSMZ, Braunschweig, Germany) was stored at $-80{ }^{\circ} \mathrm{C}$ in $20 \%(v / v)$ glycerol (Fisher Scientific, Geel, Belgium). Before the experiments, bacteria were subcultured twice on the complex marine medium Våatanen nine salt solution (VNSS) [24] supplemented with $15 \mathrm{~g} / \mathrm{L}$ agar (VWR International S.A.A., Fontenay-sous-Bois, France) for $24 \mathrm{~h}$ at $25^{\circ} \mathrm{C}$. An overnight culture was then prepared by transferring colonies from a VNSS agar plate to $150 \mathrm{~mL}$ of VNSS medium and incubating at $25{ }^{\circ} \mathrm{C}$ with agitation.

Cyanobium sp. LEGE 10375 was isolated from an intertidal zone, on a marine sponge, at São Bartolomeu do Mar beach (Esposende, Braga, Portugal) (41.57378 N 8.798556 W). This cyanobacterium was obtained from the Blue Biotechnology and Ecotoxicology Culture Collection (LEGE-CC), located at the Interdisciplinary Centre of Marine and Environmental Research (CIIMAR), Matosinhos, Portugal [25]. Cyanobacteria were grown in $750 \mathrm{~mL}$ of Z8 medium supplemented with $25 \mathrm{~g}$ /L of synthetic sea salts (Tropic Marin, Montague, MA, USA) and B12 vitamin (Sigma Aldrich, Merck, Saint Louis, MO, USA), at $25^{\circ} \mathrm{C}$ under $14 \mathrm{~h}$ light (10-30 mol photons $\left./ \mathrm{m}^{2} \mathrm{~s}, \lambda=380-700 \mathrm{~nm}\right) / 10 \mathrm{~h}$ dark cycles [9].

\subsection{Single- and Dual-Species Biofilm Formation}

The ability of P. tunicata and Cyanobium sp. alone and in co-culture to colonize the coated surface was monitored for 7 weeks (49 days) using 12-well microplates (VWR International, Carnaxide, Portugal) under controlled hydrodynamic conditions. Biofilm development was followed for 49 days because this period corresponds to approximately half of the minimal economically viable interval accepted for the maintenance of underwater systems [22] and hull cleaning [26]. Biofilms were grown in an orbital shaker with a $25 \mathrm{~mm}$ diameter (Agitorb 200ICP, Norconcessus, Ermesinde, Portugal) at $185 \mathrm{rpm}$, which corresponds to an average shear rate of 40 /s and a maximum of 120 /s [13,20], comprising the shear rate value of 50/s estimated for a ship in a harbor [27].

P. tunicata DSM 14096 and Cyanobium sp. LEGE 10375 suspensions at a final concentration of $1 \times 10^{8} \mathrm{CFU} / \mathrm{mL}$ were prepared in VNSS medium from the corresponding overnight cultures. For Cyanobium sp., a $1 \times 10^{8} \mathrm{CFU} / \mathrm{mL}$ cell suspension was also prepared in Z8 medium as a growth control (Figure S1) since this is the recommended medium for the cultivation of these species of cyanobacteria [9]. For dual-species biofilms of P. tunicata and Cyanobium sp., both cell suspensions prepared in VNSS medium were mixed at a 1:1 ratio [28] in order to obtain a final concentration of $1 \times 10^{8} \mathrm{CFU} / \mathrm{mL}$. The coated glass coupons were first fixed to the plate wells using double-sided adhesive tape and UV sterilized for $30 \mathrm{~min}$ [20]. Then, $3 \mathrm{~mL}$ of each single- and dual-species culture were added to the wells, and the microplates were incubated with alternate cycles of $14 \mathrm{~h}$ light/10 h dark, at $25{ }^{\circ} \mathrm{C}$ for 49 days. Additionally, $3 \mathrm{~mL}$ of VNSS medium were added to the wells containing coated glass coupons in order to control the surfaces' sterility throughout the 49 days of the experiment (negative control). Two coupons for each experimental condition were removed every 7 days for biofilm analysis. During the incubation period, the culture medium was carefully replaced twice a week. Three independent biofilm formation assays, with two technical replicates each, were performed. 


\subsection{Biofilm Analysis}

The removed coupons were gently washed with $3 \mathrm{~mL}$ of $0.85 \%(v / v)$ sterile saline solution to remove non-attached microorganisms [9] and analyzed regarding the number of biofilm cells, biofilm wet weight, and biofilm thickness. The biofilm architecture was also evaluated through confocal laser scanning microscopy (CLSM) after 21, 35, and 49 days.

\subsubsection{Cell Density and Wet Weight}

For total cell counting, coupons were vortexed in $2 \mathrm{~mL}$ of saline solution for $3 \mathrm{~min}$ to release and homogenize the biofilm cells. Then, $10 \mu \mathrm{L}$ of each cell suspension (single- or dual-species) were placed on a Neubauer chamber (Zuzi, Lisboa, Portugal) and counting was performed under a light microscope with a $10 \times$ objective (Nikon Eclipse LV100 microscope, Nikon Corporation, Tokyo, Japan).

The coupons were weighed on an analytical balance, and the biofilm wet weight was determined by the difference between the weight before inoculation and the weight on the sampling day.

\subsubsection{Thickness}

Biofilm thickness was obtained through optical coherence tomography (OCT) (Thorlabs Ganymede Spectral Domain Optical Coherence Tomography system, Thorlabs GmbH, Dachau, Germany) as indicated by Faria et al. [9]. The plate wells were filled again with saline solution, and a minimum of five different fields of view (2D images) per single- and dual-species biofilm were captured on each sampling day. The processing and analysis of OCT images were performed using a routine developed in the Image Processing Toolbox from MATLAB 8.0 and Statistics Toolbox 8.1 (The MathWorks, Inc., Natick, MA, USA) [13].

\subsubsection{Confocal Laser Scanning Microscopy (CLSM)}

Single- and dual-species biofilms of P. tunicata and Cyanobium sp. were imaged using a Leica TCS SP5 II confocal laser scanning microscope (Leica Microsystems, Wetzlar, Germany) after 21, 35, and 49 days of biofilm formation. Biofilm samples were counterstained with Syto9 (Thermo Fisher Scientific, Waltham, MA, USA), a green cell-permeant nucleic acid marker, for $10 \mathrm{~min}$ at room temperature, and then scanned at $40 \times$ magnitude with an HCX PL APO CS $40 \times / 1.10$ CORR water objective lens at an excitation wavelength of $488 \mathrm{~nm}$ (argon laser). The emitted fluorescence was recorded within the range of 460 to $575 \mathrm{~nm}$. A minimum of five stacks of horizontal plane images $(512 \times 512$ pixels, corresponding to $387.5 \mu \mathrm{m} \times 387.5 \mu \mathrm{m}$ ) with a $z$-step of $1 \mu \mathrm{m}$ were acquired for each biofilm sample.

Three-dimensional (3D) projections of biofilm structures were reconstructed from the CLSM acquisitions using the blend mode of the "Easy 3D" function of IMARIS 9.1 software (Bitplane, Zurich, Switzerland). Biofilm biovolume $\left(\mu \mathrm{m}^{3} / \mu \mathrm{m}^{2}\right)$ was extracted from confocal image series with the plug-in COMSTAT2 run in Image $1.48 \mathrm{v}$ software, as previously described [29]. Biovolume represents the total amount of biofilm $\left(\mu \mathrm{m}^{3}\right)$ in the substratum area of the image stack $\left(\mu \mathrm{m}^{2}\right)$.

\subsection{Statistical Analysis}

Descriptive statistics were used to compute mean and standard deviation for all parameters evaluated in single- and dual-species biofilms: the total cell number (Figure 1A), wet weight (Figure 1B), thickness (Figure 1C), and biovolume (Figure 2A). Since the variable distribution was normal, one-way ANOVA analysis was used to compare biofilm formation between single- (P. tunicata or Cyanobium sp.) and dual-species biofilms (P. tunicata-Cyanobium sp.) on each experimental day. For each time point, letters were assigned in alphabetic order from the highest to the lowest value (from a to c) as long as statistically significant differences existed between the biofilms with a confidence level greater than 95\% $(p<0.05)$. 
Linear regression models (LRMs) were applied between the biofilm cells, wet weight, thickness, and biovolume, and single- and dual-species biofilms (Figure 1D-F, and Figure 2B). Models were adjusted for incubation days. For all LRMs, dual-species biofilms were used as the reference condition. Results are presented as beta estimates $(\beta)$ and the corresponding 95\% confidence intervals (95\% CI).

Data analysis was performed using the IBM SPSS Statistics version 24.0 for Windows (IBM SPSS, Inc., Chicago, IL, USA).

\section{Results}

In this study, the ability of two common microfouler organisms, a marine bacterium and a cyanobacterium (P. tunicata and Cyanobium sp.) to develop single- and dual-species biofilms in epoxy-coated surfaces was analyzed. The importance of conducting multispecies biofilm assays for the initial screening of the antifouling potential of novel surface coatings for marine settings was assessed.

Figure 1 presents the number of biofilm cells, wet weight, and thickness determined for single- (P. tunicata or Cyanobium sp. LEGE 10375) and dual-species biofilms (P. tunicataCyanobium sp. LEGE 10375) grown for 49 days under hydrodynamic conditions that mimic the aquatic environment.

(A)

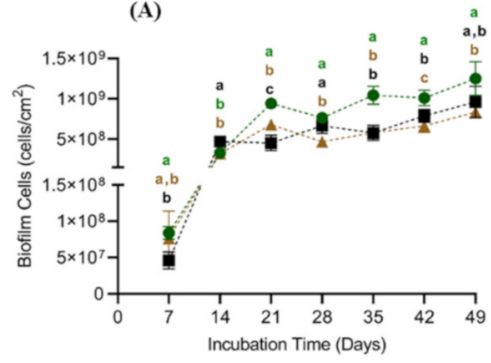

(D)

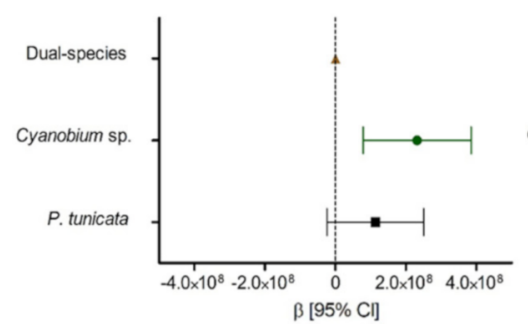

(B)

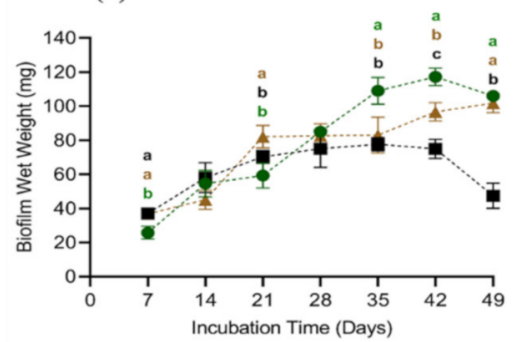

(E)

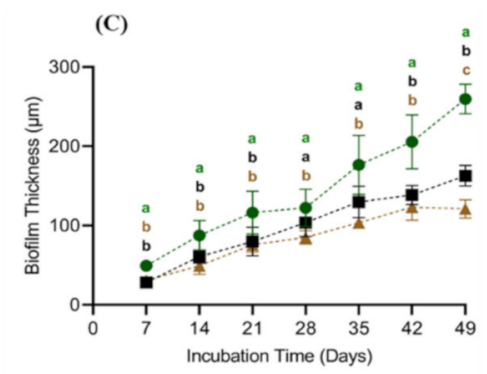

(F)
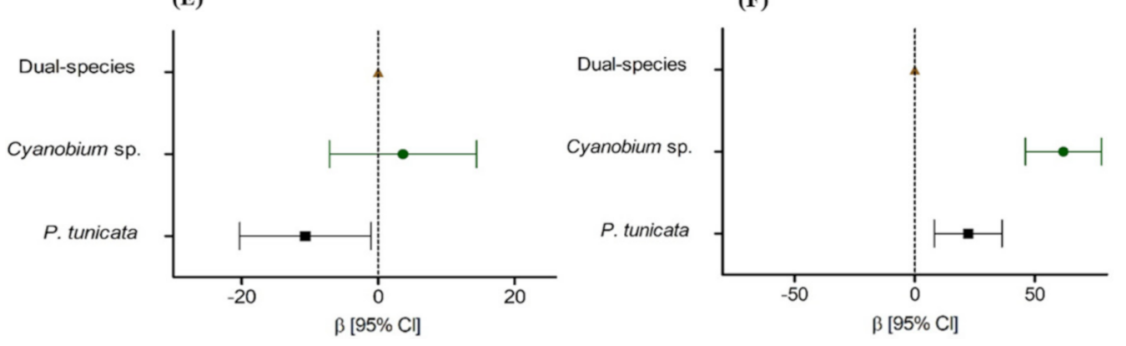

Figure 1. (A-C) Single- and dual-species biofilm formation on gel-coated glass surfaces for 49 days: •-Cyanobium sp. LEGE 10375, - -Pseudoalteromonas tunicata, and $\Delta$-Pseudoalteromonas tunicata-Cyanobium sp. LEGE 10375. The biofilm parameters are (A) number of cells, (B) wet weight, and (C) thickness. Letters were assigned in alphabetic order from the highest to the lowest value (from a to $\mathrm{c}$ ) for each time point. These assignments were made as long as statistically significant differences existed between the biofilms with a confidence level greater than $95 \%(p<0.05)$. The color of the letters allows for association with the type of biofilm formed (green-Cyanobium sp. LEGE 10375, black-Pseudoalteromonas tunicata, and brown-Pseudoalteromonas tunicata-Cyanobium sp. LEGE 10375). The means \pm SDs for three independent experiments are illustrated. (D-F) Association between the (D) number of biofilm cells, (E) wet weight, and (F) thickness, and single- and dual-species biofilms. Dual-species biofilms were used as the reference condition. Linear regression models were adjusted for incubation days. Results are represented as beta estimates $(\beta)$ and the corresponding 95\% confidence interval (95\% CI).

In general, the cell number of Cyanobium sp. LEGE 10375 biofilms was higher than for P. tunicata and dual-species biofilms (on average $33 \%$ and $27 \%$, respectively), with significant statistical differences at almost all sampling points $(p<0.05$, Figure $1 \mathrm{~A})$. While single-species biofilms of $P$. tunicata and dual-species biofilms grew markedly between days 7 and 14 (approximately $1 \log$ cells $/ \mathrm{cm}^{2}$ ), tending towards similar growth kinetics and stabilization by the end of the experiment, the cell number in cyanobacterial biofilms increased exponentially until day 21 , reaching $9.4 \times 10^{8} \pm 3.3 \times 10^{5}$ cells $/ \mathrm{cm}^{2}$, which 
is $52 \%$ and $28 \%$ higher than the value for P. tunicata biofilms and dual-species biofilms, respectively, at the same time point $(p<0.05)$.

The wet weight of $P$. tunicata single-species biofilms and mixed biofilms increased to an average value of $76 \mathrm{mg}$ on day 21 (Figure 1B). This biofilm parameter remained practically constant in the following two weeks for both types of biofilm. However, its behavior changed with the gradual increase in the wet weight of dual-species biofilms until day 49 , and the abrupt reduction of the weight of $P$. tunicata biofilms (to about half at the end of the experiment). With regard to cyanobacterial biofilms, their wet weight increased linearly until day 35 , exceeding by $26 \%$ the wet weight of bacterial and bacteria-cyanobacteria biofilms $(p<0.01)$.

Concerning biofilm thickness, there was a linear increase during the 7-week assay in the three types of analyzed biofilms, P. tunicata and Cyanobium sp. single-species biofilms and P. tunicata-Cyanobium sp. biofilms (Figure 1C). Moreover, cyanobacterial biofilms were significantly thicker than P. tunicata biofilms (on average $31 \%, p<0.05$ for five out of seven time points) and dual-species biofilms (on average $42 \%, p<0.05$ for all time points). This difference between Cyanobium sp. biofilms and both $P$. tunicata singleand dual-species biofilms was particularly noticeable from day 28 onwards when the thickness of cyanobacterial biofilms increased from about $100 \mu \mathrm{m}$ to the maximum value of $260 \mu \mathrm{m}$ at day 49 (37\% and 53\% higher than P. tunicata single- and dual-species biofilms, respectively, $p<0.01)$. It is also possible to observe that the thickness profile of $P$. tunicata biofilms was similar to the mixed biofilms, although slightly higher thickness values were obtained for the single-species biofilms (on average 17\%; $p<0.05$ for three of the seven experimental points).

Regarding the biovolume obtained from the CLSM data acquired (Figure 2A), cyanobacterial biofilms displayed on average $50 \%$ more biomass than axenic $P$. tunicata biofilms and dual-species biofilms, regardless of the sampling day $(p<0.05)$.
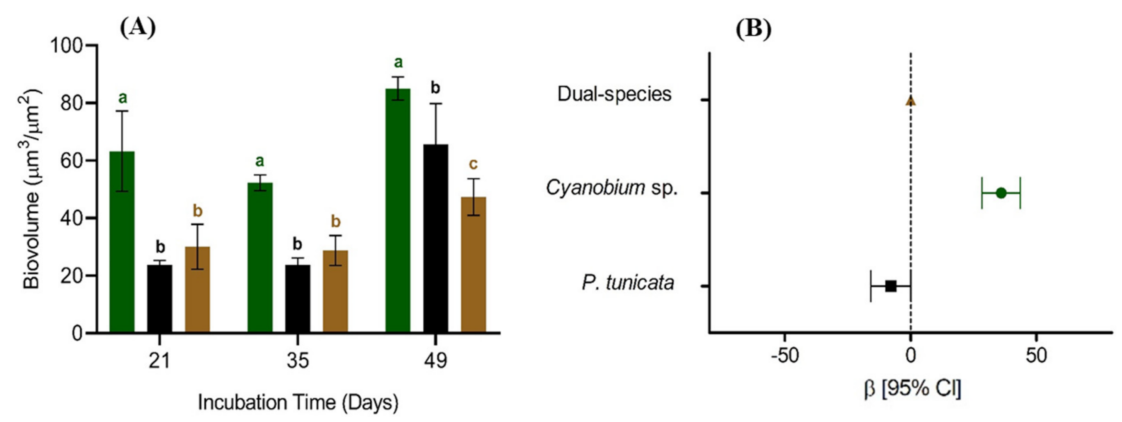

Figure 2. (A) Biovolume of single- and dual-species biofilms established on gel-coated glass surfaces at days 21, 35, and 49: —-Cyanobium sp. LEGE 10375, ——Pseudoalteromonas tunicata, and — Pseudoalteromonas tunicata-Cyanobium sp. LEGE 10375. Letters were assigned in alphabetic order from the highest to the lowest value (from a to $c$ ) for each time point. These assignments were made as long as statistically significant differences existed between the biofilms with a confidence level greater than $95 \%(p<0.05)$. The means \pm SDs for three independent experiments are illustrated. (B) Association between the biovolume and single- and dual-species biofilms. Dual-species biofilm was used as the reference condition. Linear regression models were adjusted for incubation days. Results are represented as beta estimates $(\beta)$ and the corresponding $95 \%$ confidence interval $(95 \% \mathrm{CI})$.

In an attempt to clarify the relationship between the biofilm parameter (number of biofilm cells, weight, thickness, or biovolume) and the community complexity (single- or dual-species biofilms), linear regression models were used (Figure 1D-F, and Figure 2B). The results from the LRMs have positive or negative results whenever a given condition generated an increase or decrease, respectively, in the analysis parameter $(\beta)$ in comparison with the reference condition (in this case, the dual-species biofilms). In general, Cyanobium sp. biofilms formed on gel-coated surfaces were significantly associated with a larger number of cells $\left(\beta=2.32 \times 10^{8}\right.$ cells $\left./ \mathrm{cm}^{2}, 95 \% \mathrm{CI}=\left[7.84 \times 10^{7}: 3.85 \times 10^{8}\right]\right)$, 
thickness $(\beta=61.89 \mu \mathrm{m}, 95 \% \mathrm{CI}=[46.07: 77.71])$, and biovolume $\left(\beta=36.01 \mu \mathrm{m}^{3} / \mu \mathrm{m}^{2}, 95 \%\right.$ $\mathrm{CI}=[28.38: 43.64]$ ) when compared to dual-species biofilms (Figure 1D,F, and Figure 2B). Likewise, the wet weight of Cyanobium sp. biofilms was higher than dual-species biofilms $(\beta=3.64 \mathrm{mg}, 95 \% \mathrm{CI}=[-7.13: 14.4])$ (Figure $1 \mathrm{E})$. Concerning the $P$. tunicata biofilms, only the biofilm thickness was significantly higher than dual-species biofilms $(\beta=22.27 \mu \mathrm{m}$, $95 \% \mathrm{CI}=[8.12: 36.42]$ ) (Figure 1F). P. tunicata biofilms were significantly associated with a lower biofilm wet weight $(\beta=-10.63 \mathrm{mg}, 95 \% \mathrm{CI}=[-20.27:-1.00])$ and biovolume $\left(\beta=-7.87 \mu \mathrm{m}^{3} / \mu \mathrm{m}^{2}, 95 \% \mathrm{CI}=[-15.80: 0.00]\right)$ when compared to dual-species biofilms (Figures $1 \mathrm{E}$ and $2 \mathrm{~B}$ ).

The spatial distribution of single- and dual-species biofilms developed on gel-coated surfaces was evaluated by CLSM (Figure 3). Regardless of incubation day, cyanobacterial biofilms exhibited more biomass and thickness than $P$. tunicata biofilms and dual-species biofilms. Confocal microscopic images corroborate the results presented in Figures 1 and 2 by showing that Cyanobium sp. LEGE 10375 biofilms were the worst-case population conditions, i.e., the conditions that had a greater biofilm amount on the surface material under test. P. tunicata alone had an intermediate biofilm-forming ability, while the bacteriumcyanobacterium mixture developed less dense and thinner biofilms when compared to the single-species biofilms of the same marine strains (Figure 3).

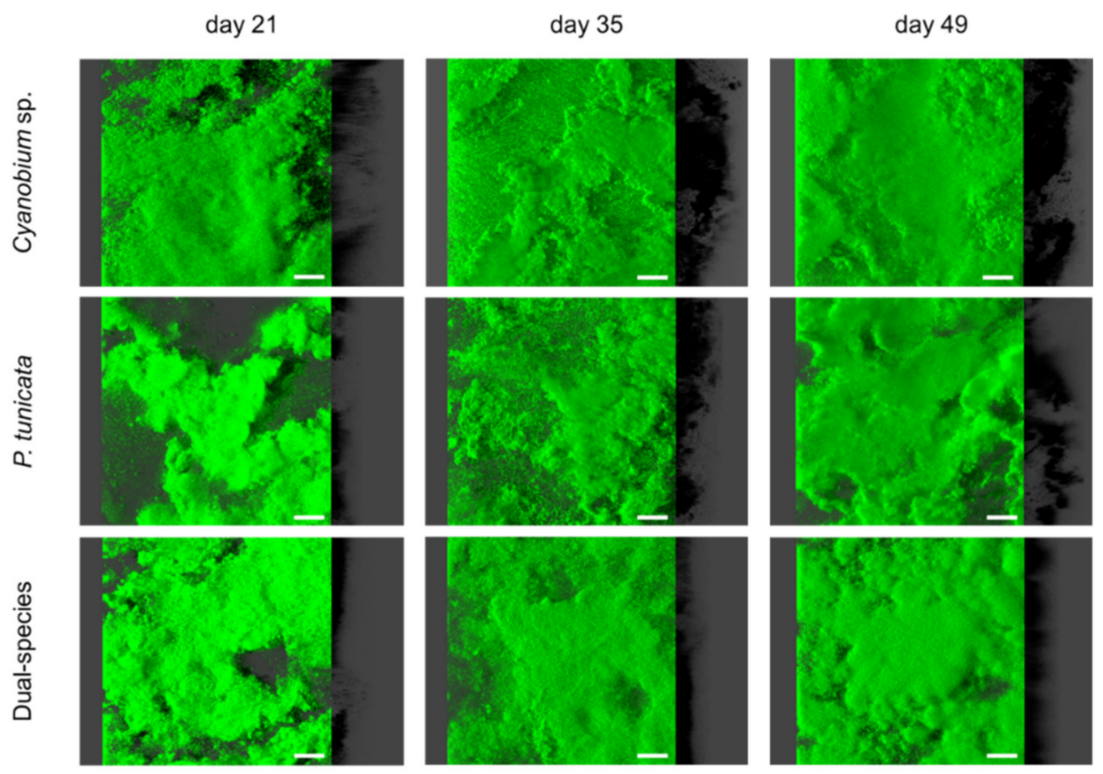

Figure 3. 3D projections of single- (Cyanobium sp. and P. tunicata) and dual-species biofilms formed on gel-coated glass surfaces after 21,35 , and 49 days. The representative images were obtained from confocal $z$-stacks using IMARIS software and present an aerial view of the biofilms (shadow projection on the right). The white scale bar corresponds to $50 \mu \mathrm{m}$.

\section{Discussion}

Present-day awareness of biofilm formation on man-made structures in aquatic environments has prompted the scientific community to develop an increasing number of new materials with antifouling features. Indeed, the development of AF coatings that can prevent organism adhesion or weaken the biofilm structure has emerged as a promising approach to overcome problems associated with fouling in a marine context, including the reduction of ship speed and the consequent increase in operating costs [3]. In recent years, modern chemical research has played a prominent role in this area through the synthesis of eco-friendly coatings with improved foul release performance, and also antifouling properties. Green chemistry has been successful in designing several AF coatings for large and small vessels made of different materials (steel, aluminum, wood, etc.) that do not contain toxic compounds, limit the extent of environmental damage produced by the 
transportation of non-indigenous species, and improve the hydrodynamic performance of vessels, ensuring significant fuel savings [30].

The complexity of marine fouling communities is significant and results from changes in environmental conditions, such as water turbulence, temperature, salinity, light regime, and number of nutrients [1]. Thus, it is within this complex system that marine coatings preventing or reducing biofouling must perform and ultimately be tested. The use of artificial panels to study biofouling communities in natural environments is important for the evaluation of antifouling systems [7,31]. However, it is an arduous task in the development of novel coatings to begin field testing straight away since some of these materials may be very expensive and hard to produce in large quantities. Additionally, there is the issue of a potential release of toxic substances to the marine environment, which must be avoided [12]. Furthermore, the sheer number of formulations that are created with the advent of combinatorial approaches requires initial screening in the laboratory. The laboratory assays are relatively quick and easy, so they should be applied in order to eliminate coating formulations that may be expected to have poor antifouling and physical performances in the in vivo ecosystem [32].

Although most in vitro tests described in the literature grossly simplify the dynamics of fouling in the marine environment, our research group has been particularly concerned in recent years about the influence of hydrodynamics on cyanobacterial and Pseudoalteromonas sp. biofilm formation $[9,13,20]$. The hypothesis for the current study was that differences in the degree of complexity of marine cultures (single- or dual-species cultures) might impact the preliminary conclusions about the efficacy of new AF coatings. To test this hypothesis, an epoxy resin surface typically used to coat boat hulls was tested with singlespecies (Pseudoalteromonas tunicata or Cyanobium sp. LEGE 10375) and dual-species cultures (P. tunicata-Cyanobium sp. LEGE 10375). Our study demonstrated that the growth kinetics of single-species biofilms of a cyanobacterium was different from dual-species biofilms containing this marine microorganism. On the contrary, the growth of $P$. tunicata biofilms over 7 weeks occurred similarly to dual-species biofilms. In general, Cyanobium sp. biofilms presented higher cell density, biomass, and thickness than the dual-species biofilms and the single-species biofilms formed by $P$. tunicata. The decrease in the parameters of dual-species biofilms compared to Cyanobium sp. biofilms may be related to the presence of P. tunicata. Several authors have recognized this microorganism as a superior competitor able to adapt to high-density communities on surfaces [33,34]. Additionally, in mixed-species biofilms, P. tunicata can inhibit the competing strains. This dominance may be attributed to the ability of this marine bacterium to rapidly form microcolonies and to its capacity for producing extracellular antimicrobial compounds [34].

To the best of our knowledge, this is one of the few works that highlights the importance of shorter laboratory-scale trials to study marine biofilms and discloses that monocultures at this scale are as important as, or more important than, mixed cultures when the performance of an antibiofilm material for marine applications is evaluated. There is a preconceived idea among biofilm researchers that microbial diversity in biofilm communities is associated with the enhanced survival and growth of the individual biofilm populations $[35,36]$. It has also been shown that this diversity may lead to enhanced tolerance towards antimicrobial compounds [28,37]. For example, $63 \%$ of soil isolates exhibited cooperation when grown as four-member consortia, as determined by quantifying total biofilm biomass by crystal violet staining [36]. Similarly, on average, $54 \%$ of the multispecies biofilms formed by isolates from the same habitat exhibited increased biomass relative to when grown as single-species biofilms [38]. In a recent study, the influence of intraspecies diversity in biofilm populations composed of up to six different Escherichia coli strains isolated from urine was evaluated [19]. Briefly, with the increasing number of strains in a biofilm, an increase in cell culturability and a decrease in matrix production were observed. This suggests that increased genotypic diversity in those biofilms led E. coli to direct energy towards the production of its offspring, in detriment of the production of public goods (i.e., matrix components) [19]. Thus, the available data indicate that biofilm 
development in situations of high microbial diversity may be higher or lower than when each species is individually assessed as a result of the type of interspecies interactions that may occur (cooperation or competition) [39].

Another technical challenge of performing in vitro assays with multispecies biofilms is the inoculum preparation, as the relative proportions of each type of organism may be difficult to replicate. The fact that these organisms may be in different physiological states further complicates the problem. A common strategy is to use approximately the same cellular concentration of each organism $[28,40]$, which is, of course, a simplification.

In this work, the cyanobacterium alone produced more biofilm than the co-culture of P. tunicata and Cyanobium sp. It has been suggested, for antibiofilm assays, that conditions promoting microbial growth and biofilm formation are desirable so that the positive controls are reproducible $[41,42]$ and the differences observed between controls and developed surfaces are effective. Our results indicate that for initial screening, it is probably better to start with a single representative organism (a marine bacterium, a cyanobacterium, or even diatoms) and compare the AF behavior of the coating to a control surface. Parallel studies using a different organism (for instance, marine larvae [43]) may be performed to strengthen the results. After this initial screening, field tests are necessary and can be performed on a reduced number of surfaces to confirm the real AF activity in the correct environment.

\section{Conclusions}

Even though they are unable to replicate the real marine environment, in vitro tests are a useful tool for initial screening and comparing the effectiveness of antifouling surfaces, having the advantage of easily assessing a broad spectrum of marine conditions.

There is a pressing need for more laboratory work focused on the interactions and dynamics within multispecies biofilms because they are the dominant form in nature, and it is necessary to successfully prevent or control their development. However, when the main goal is to search for new antifouling surfaces, the present study showed that attention should be given to single-species biofilms, in particular those formed by cyanobacteria, since they can create the worst-case scenarios needed for robust testing of the AF performance. In fact, monocultures of P. tunicata and Cyanobium sp. caused denser and thicker biofilms on the polymeric coating than co-cultures with the same marine strains.

The single-strain strategy represents a good compromise between the high complexity of in vivo marine ecosystems and the convenience of in vitro testing, overcoming the experimental limitations in replicating the cellular concentration of each organism in a dual-species biofilm. Further experiments using a different microfouler (e.g., diatoms), or even a macrofouler (e.g., larvae), should be conducted to support the results.

Supplementary Materials: The following are available online at https:/ / www.mdpi.com/2079-641 2/11/1/90/s1. Figure S1. Number of Cyanobium sp. cells growing in Våatanen nine salt solution (VNSS) and Z8 medium attached on polymer epoxy resin after 49 days of incubation.

Author Contributions: Conceptualization, S.I.F. and F.J.M.M.; Methodology, S.I.F. and L.C.G.; Formal analysis, S.I.F., L.C.G. and R.T.-S.; Investigation, S.I.F., L.C.G. and R.T.-S.; Resources, J.M., V.V. and F.J.M.M.; Data curation, S.I.F.; Writing-original draft preparation, S.I.F. and L.C.G.; Writing-review and editing, R.T.-S., J.M., V.V. and F.J.M.M.; Supervision, F.J.M.M. All authors have read and agreed to the published version of the manuscript.

Funding: This research was funded by Base Funding-UIDB/00511/2020 of the Laboratory for Process Engineering, Environment, Biotechnology and Energy (LEPABE) funded by national funds through the FCT/MCTES (PIDDAC), “CVMAR+I-Industrial Innovation and Marine Biotechnology Valorization" project, funded by INTERREG V Espanha Portugal (POCTEP) (0302_CVMAR_I_1_P), and UIDB/04423/2020. L.C.G. thanks the Portuguese Foundation for Science and Technology (FCT) for the financial support of her work contract through the Scientific Employment Stimulus-Individual Call-[CEECIND/01700/2017]. R.T.-S. acknowledges the receipt of a junior researcher fellowship from the Project PTDC/BII-BIO/29589/2017-POCI-01-0145-FEDER-029589, funded by FEDER funds through COMPETE2020-Programa Operacional Competitividade e Internacionalização (POCI) and by national funds (PIDDAC) through FCT/MCTES. 
Institutional Review Board Statement: Not applicable.

Informed Consent Statement: Not applicable.

Data Availability Statement: Data is contained within the article or Supplementary Materials.

Conflicts of Interest: The authors declare no conflict of interest.

\section{References}

1. Caruso, G. Microbial Colonization in Marine Environments: Overview of Current Knowledge and Emerging Research Topics. J. Mar. Sci. Eng. 2020, 8, 78. [CrossRef]

2. Carvalho, C.C. Marine biofilms: A successful microbial strategy with economic implications. Front. Mar. Sci. 2018, 5, 126. [CrossRef]

3. Tian, L.; Yin, Y.; Jin, H.; Bing, W.; Jin, E.; Zhao, J.; Ren, L. Novel marine antifouling coatings inspired by corals. Mater. Today Chem. 2020, 17, 100294. [CrossRef]

4. Brooks, S.; Waldock, M. The use of copper as a biocide in marine antifouling paints. In Advances in Marine Antifouling Coatings and Technologies; Hellio, C., Yebra, D., Eds.; Woodhead Publishing: Cambridge, UK, 2009; pp. 492-521.

5. Lacoursière-Roussel, A.; Bock, D.G.; Cristescu, M.E.; Guichard, F.; McKindsey, C.W. Effect of shipping traffic on biofouling invasion success at population and community levels. Biol. Invasions 2016, 18, 3681-3695. [CrossRef]

6. Miller, R.J.; Adeleye, A.S.; Page, H.M.; Kui, L.; Lenihan, H.S.; Keller, A.A. Nano and traditional copper and zinc antifouling coatings: Metal release and impact on marine sessile invertebrate communities. J. Nanoparticle Res. 2020, 22, 1-15. [CrossRef]

7. Silva, E.R.; Ferreira, O.; Ramalho, P.A.; Azevedo, N.F.; Bayón, R.; Igartua, A.; Bordado, J.C.; Calhorda, M.J. Eco-friendly non-biocide-release coatings for marine biofouling prevention. Sci. Total Environ. 2019, 650, 2499-2511. [CrossRef]

8. Amara, I.; Miled, W.; Slama, R.B.; Ladhari, N. Antifouling processes and toxicity effects of antifouling paints on marine environment. A review. Environ. Toxicol. Pharmacol. 2018, 57, 115-130. [CrossRef]

9. Faria, S.I.; Teixeira-Santos, R.; Gomes, L.C.; Silva, E.R.; Morais, J.; Vasconcelos, V.; Mergulhão, F.J.M. Experimental assessment of the performance of two marine coatings to curb biofilm formation of microfoulers. Coatings 2020, 10, 893. [CrossRef]

10. Li, Z.; Guo, Z. Bioinspired surfaces with wettability for antifouling application. Nanoscale 2019, 11, 22636-22663. [CrossRef]

11. Salta, M.; Wharton, J.A.; Stoodley, P.; Dennington, S.P.; Goodes, L.R.; Werwinski, S.; Mart, U.; Wood, R.J.; Stokes, K.R. Designing biomimetic antifouling surfaces. Philos. Trans. A Math. Phys. Eng. Sci. 2010, 368, 4729-4754. [CrossRef]

12. Zecher, K.; Aitha, V.P.; Heuer, K.; Ahlers, H.; Roland, K.; Fiedel, M.; Philipp, B. A multi-step approach for testing non-toxic amphiphilic antifouling coatings against marine microfouling at different levels of biological complexity. J. Microbiol. Methods 2018, 146, 104-114. [CrossRef] [PubMed]

13. Romeu, M.J.; Alves, P.; Morais, J.; Miranda, J.M.; De Jong, E.D.; Sjollema, J.; Ramos, V.; Vasconcelos, V.; Mergulhão, F.J.M. Biofilm formation behaviour of marine filamentous cyanobacterial strains in controlled hydrodynamic conditions. Environ. Microbiol. 2019, 21, 4411-4424. [CrossRef] [PubMed]

14. Buhmann, M.; Kroth, P.G.; Schleheck, D. Photoautotrophic-heterotrophic biofilm communities: A laboratory incubator designed for growing axenic diatoms and bacteria in defined mixed-species biofilms. Environ. Microbiol. Rep. 2012, 4, 133-140. [CrossRef] [PubMed]

15. Magana, M.; Sereti, C.; Ioannidis, A.; Mitchell, C.A.; Ball, A.R.; Magiorkinis, E.; Chatzipanagiotou, S.; Hamblin, M.R.; Hadjifrangiskou, M.; Tegos, G.P. Options and limitations in clinical Investigation of bacterial biofilms. Clin. Microbiol. Rev. $2018,31$. [CrossRef] [PubMed]

16. Burmølle, M.; Ren, D.; Bjarnsholt, T.; Sørensen, S.J. Interactions in multispecies biofilms: Do they actually matter? Trends Microbiol. 2014, 22, 84-91. [CrossRef] [PubMed]

17. Røder, H.L.; Sørensen, S.J.; Burmølle, M. Studying Bacterial Multispecies Biofilms: Where to Start? Trends Microb. 2016, 24, 503-513. [CrossRef]

18. Yu, X.; Polz, M.F.; Alm, E.J. Interactions in self-assembled microbial communities saturate with diversity. ISME J. 2019, 13, 1602-1617. [CrossRef]

19. Azevedo, A.S.; Gerola, G.P.; Baptista, J.; Almeida, C.; Peres, J.; Mergulhão, F.J.M.; Azevedo, N.F. Increased Intraspecies diversity in Escherichia coli biofilms promotes cellular growth at the expense of matrix production. Antibiotics 2020, 9, 818. [CrossRef]

20. Faria, S.I.; Teixeira-Santos, R.; Romeu, M.J.; Morais, J.; Vasconcelos, V.; Mergulhão, F.J.M. The Relative Importance of Shear Forces and Surface Hydrophobicity on Biofilm Formation by Coccoid Cyanobacteria. Polymers 2020, 12, 653. [CrossRef]

21. Taylor, D.A. Chapter 16-Engineering materials. In Introduction to Marine Engineering, 2nd ed.; Taylor, D.A., Ed.; ButterworthHeinemann: Oxford, UK, 1996; pp. 326-340.

22. Blain, S.; Guillou, J.; Tréguer, P.; Woerther, P.; Delauney, L.; Follenfant, E.; Gontier, O.; Hamon, M.; Leildé, B.; Masson, A.; et al. High frequency monitoring of the coastal marine environment using the MAREL buoy. J. Environ. Monit. 2004, 6, 569-575. [CrossRef]

23. Hoge, J.; Leach, C. Epoxy resin infused boat hulls. Reinforced Plastics 2016, 60, 221-223. [CrossRef]

24. Holmstrom, C.; James, S.; Neilan, B.A.; White, D.C.; Kjelleberg, S. Pseudoalteromonas tunicata sp. nov., a bacterium that produces antifouling agents. Int. J. Syst. Bacteriol. 1998, 48, 1205-1212. [CrossRef] [PubMed] 
25. Ramos, V.; Morais, J.; Castelo-Branco, R.; Pinheiro, Â.; Martins, J.; Regueiras, A.; Pereira, A.L.; Lopes, V.R.; Frazão, B.; Gomes, D. Cyanobacterial diversity held in microbial biological resource centers as a biotechnological asset: The case study of the newly established LEGE culture collection. J. Appl. Phycol. 2018, 30, 1437-1451. [CrossRef] [PubMed]

26. Schultz, M.P.; Bendick, J.A.; Holm, E.R.; Hertel, W.M. Economic impact of biofouling on a naval surface ship. Biofouling 2011, 27, 87-98. [CrossRef] [PubMed]

27. Bakker, D.; Van der Plaats, A.; Verkerke, G.; Busscher, H.; Van der Mei, H. Comparison of velocity profiles for different flow chamber designs used in studies of microbial adhesion to surfaces. Appl. Environ. Microbiol. 2003, 69, 6280-6287. [CrossRef]

28. Gomes, L.; Deschamps, J.; Briandet, R.; Mergulhão, F.J. Impact of modified diamond-like carbon coatings on the spatial organization and disinfection of mixed-biofilms composed of Escherichia coli and Pantoea agglomerans industrial isolates. Int. J. Food Microbiol. 2018, 277, 74-82. [CrossRef]

29. Heydorn, A.; Nielsen, A.T.; Hentzer, M.; Sternberg, C.; Givskov, M.; Ersbøll, B.K.; Molin, S. Quantification of biofilm structures by the novel computer program COMSTAT. Microbiology 2000, 146, 2395-2407. [CrossRef]

30. Ciriminna, R.; Bright, F.V.; Pagliaro, M. Ecofriendly Antifouling Marine Coatings. ACS Sustain. Chem. Eng. 2015, 3, 559-565. [CrossRef]

31. Jelic-Mrcelic, G.; Sliskovic, M.; Antolic, B. Biofouling communities on test panels coated with TBT and TBT-free copper based antifouling paints. Biofouling 2006, 22, 293-302. [CrossRef]

32. Institution, W.H.O. The Testing of Antifouling Paints. In Marine Fouling and Its Prevention; United States Naval Institute: Annapolis, MD, USA, 1952; pp. 331-348.

33. Thomas, T.; Evans, F.F.; Schleheck, D.; Mai-Prochnow, A.; Burke, C.; Penesyan, A.; Dalisay, D.S.; Stelzer-Braid, S.; Saunders, N.; Johnson, J.; et al. Analysis of the Pseudoalteromonas tunicata Genome Reveals Properties of a Surface-Associated Life Style in the Marine Environment. PLoS ONE 2008, 3, e3252. [CrossRef]

34. Rao, D.; Webb, J.S.; Kjelleberg, S. Competitive interactions in mixed-species biofilms containing the marine bacterium Pseudoalteromonas tunicata. Appl. Environ. Microbiol. 2005, 71, 1729-1736. [CrossRef] [PubMed]

35. Burmølle, M.; Webb, J.S.; Rao, D.; Hansen, L.H.; Sørensen, S.J.; Kjelleberg, S. Enhanced biofilm formation and increased resistance to antimicrobial agents and bacterial invasion are caused by synergistic interactions in multispecies biofilms. Appl. Environ. Microbiol. 2006, 72, 3916-3923. [CrossRef] [PubMed]

36. Ren, D.; Madsen, J.S.; Sørensen, S.J.; Burmølle, M. High prevalence of biofilm synergy among bacterial soil isolates in cocultures indicates bacterial interspecific cooperation. ISME J. 2015, 9, 81-89. [CrossRef] [PubMed]

37. Lee, K.W.K.; Periasamy, S.; Mukherjee, M.; Xie, C.; Kjelleberg, S.; Rice, S.A. Biofilm development and enhanced stress resistance of a model, mixed-species community biofilm. ISME J. 2014, 8, 894-907. [CrossRef]

38. Madsen, J.S.; Røder, H.L.; Russel, J.; Sørensen, H.; Burmølle, M.; Sørensen, S.J. Coexistence facilitates interspecific biofilm formation in complex microbial communities. Environ. Microb. 2016, 18, 2565-2574. [CrossRef]

39. Tan, C.H.; Lee, K.W.K.; Burmølle, M.; Kjelleberg, S.; Rice, S.A. All together now: Experimental multispecies biofilm model systems. Environ. Microb. 2017, 19, 42-53. [CrossRef]

40. Azevedo, A.S.; Almeida, C.; Gomes, L.C.; Ferreira, C.; Mergulhão, F.J.M.; Melo, L.F.; Azevedo, N.F. An in vitro model of catheterassociated urinary tract infections to investigate the role of uncommon bacteria on the Escherichia coli microbial consortium. Biochem. Eng. J. 2017, 118, 64-69. [CrossRef]

41. Martín-Rodríguez, A.J.; González-Orive, A.; Hernández-Creus, A.; Morales, A.; Dorta-Guerra, R.; Norte, M.; Martín, V.S.; Fernández, J.J. On the influence of the culture conditions in bacterial antifouling bioassays and biofilm properties: Shewanella algae, a case study. BMC Microb. 2014, 14, 102. [CrossRef]

42. Briand, J.-F. Marine antifouling laboratory bioassays: An overview of their diversity. Biofouling 2009, 25, 297-311. [CrossRef] [PubMed]

43. Dobretsov, S.; Rittschof, D. Love at first taste: Induction of larval settlement by marine microbes. Int. J. Mol. Sci. 2020, $21,731$. [CrossRef] [PubMed] 